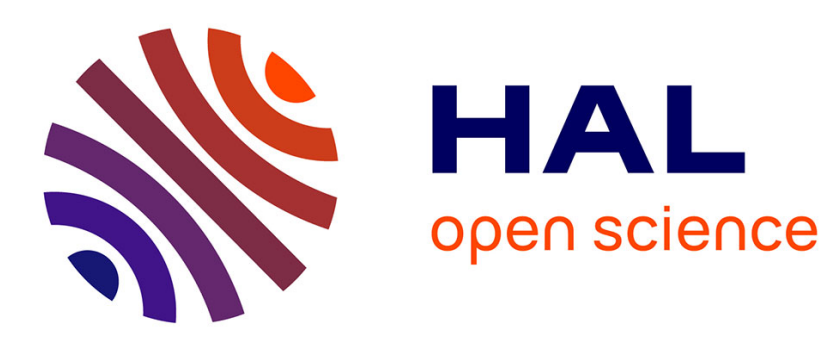

\title{
Fabrication of arrays of superconducting microbridges
}

\author{
J.E. Mooij, C.A. Gorter, J.E. Noordam
}

\section{To cite this version:}

J.E. Mooij, C.A. Gorter, J.E. Noordam. Fabrication of arrays of superconducting microbridges. Revue de Physique Appliquée, 1974, 9 (1), pp.173-177. 10.1051/rphysap:0197400901017300 . jpa-00243732

\section{HAL Id: jpa-00243732 https://hal.science/jpa-00243732}

Submitted on 1 Jan 1974

HAL is a multi-disciplinary open access archive for the deposit and dissemination of scientific research documents, whether they are published or not. The documents may come from teaching and research institutions in France or abroad, or from public or private research centers.
L'archive ouverte pluridisciplinaire HAL, est destinée au dépôt et à la diffusion de documents scientifiques de niveau recherche, publiés ou non, émanant des établissements d'enseignement et de recherche français ou étrangers, des laboratoires publics ou privés. 


\title{
FABRICATION OF ARRAYS OF SUPERCONDUCTING MICROBRIDGES
}

\author{
J. E. MOOIJ, C. A. GORTER and J. E. NOORDAM
}

Laboratorium voor Technische Natuurkunde

Technische Hogeschool, Delft, The Netherlands

\begin{abstract}
Résumé. - Deux méthodes ont été développées pour fabriquer des microponts supraconducteurs. Dans la première, on utilise une pointe de diamant pour rayer la couche mince de métal. A l'aide d'un dispositif spécial à ressort, on peut choisir la largeur du micropont et réaliser des réseaux de microponts. La distance minimale entre micropont est alors de $4 \mu$, la largeur d'un micropont $0,5 \mu$. La seconde fait appel à l'optique électronique; elle permet de fabriquer des microponts de plus petites dimensions et peut facilement produire des réseaux de microponts.
\end{abstract}

\begin{abstract}
Two methods have been developed to fabricate superconducting microbridges, i. e. scratching with a diamond point and electron-optical imaging on an electron-sensitive film. With the scratching technique, utilizing a special plate spring arrangement to determine the bridge width, arrays of microbridges have been fabricated. Distances between bridges can be varied at will from $4 \mu \mathrm{m}$ upwards. Bridge dimensions are approximately $0.5 \mu \mathrm{m}$. With electron-optical imaging smaller bridges can be fabricated; the method can easily be extended to the fabrication of arrays.
\end{abstract}

1. Introduction. - Several experiments have indicated that multiple Josephson junctions offer interesting possibilities both as emitters and detectors of high frequency radiation. It has been shown [1], [2], [3] that multiple junctions, if coupled to a radiation field, can enter a " correlated " or " superradiant " state in which the phase difference across each junction is synchronized to the local field at the position of that junction. Except for measurements on granular films, experiments have been restricted to oxide junctions and point contacts. The physical dimensions of these two latter types offer only restricted possibilities of varying the distance between junctions. With granular films the pattern of junctions is determined by the film properties.

A type of quantum interference device that lends itself very well to multiplication in well-defined patterns is the superconducting microbridge. Several methods of fabricating microbridges have been reported in the literature [4]. We developed two techniques which both can be employed to produce planar arrays of bridges. With one method, scratches are made in the metal film with a diamond point while the other method employs electron-optical imaging on an electron-sensitive film (similar to photo resist methods). The first method is described in section 2, the second in section 3 . Some initial results are given in section 4, along with some considerations as to the possible ways of using these arrays.

2. Scratching apparatus. - For our diamond scratching technique a special apparatus was built, a schematic view of it is given in figure 1 . The arm A

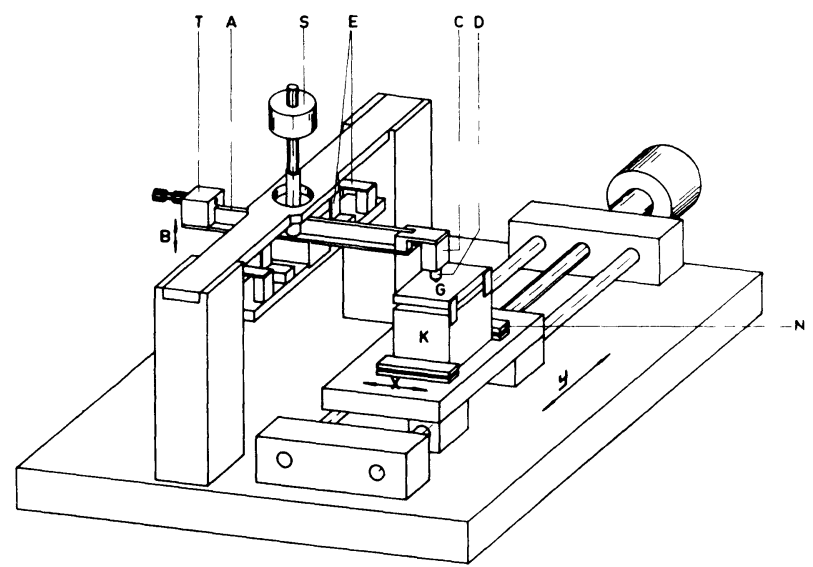

Fig. 1. - Schematic view of the scratching apparatus. A diamond point $\mathrm{D}$ is employed to produce a scratch on a metal film on table G. By interrupting the scratch a small microbridge is produced.

is attached to the support beam by a plate spring bearing of four plate springs on either side. This system allows rotation about one axis but is very rigid in all other respects. By adjustment of the weights $T$ in horizontal and $\mathrm{S}$ in vertical direction the centre of gravity of the arm is made to lie on the rotation axis. A diamond point $\mathrm{D}$, fixed to a small goniometer head $\mathrm{C}$, is the scratching tool. The diamond can be rotated about three mutually perpendicular axes to obtain the most favourable orientation relative to the metal film to be scratched. The vertical cutting force is delivered by a small weight (typically $0.3 \mathrm{~g}$ ) on top of the arm. On the opposite end of the arm 
an electrical lift mechanism is available, capable of lowering the diamond point very slowly.

The metal film on its supporting table $G$ can be moved horizontally in $\mathrm{X}$ and $\mathrm{Y}$ directions. Scratching is normally performed in the $\mathrm{X}$ direction, driven by a stepping motor. In principle, it would be possible to produce small bridges by the following procedure : scratch a certain distance, stop the motor, lift the diamond point, move the substrate a very small distance, put the point down again and scratch on. However, as we wanted a reproducible process, we did not want to rely on the transmission of the motor drive to the carriage to render the small displacement determining the width of the microbridge. Therefore a special arrangement was built, figure $2 . \mathrm{K}$ is the carriage that is moved by the stepping motor. The substrate $F$ is fixed to a table $G$ which is supported by three relatively short and thick plate springs $H$. From the middle of the table $G$ a long and thin plate spring $I$ is extending downwards. The ratio of stiffnesses of the system of springs $H$ to spring I is $1000: 1$. In this way, if the bottom end of spring I is moved over $1 \mathrm{~mm}$, the table $\mathrm{G}$ will move over $1 \mu \mathrm{m}$.

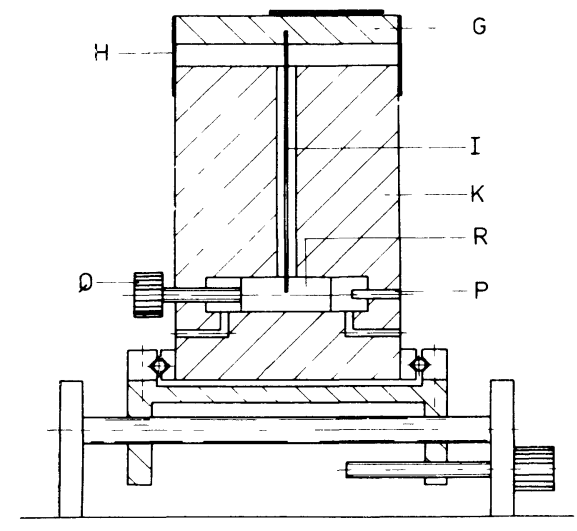

FIG. 2. - Detail of scratching apparatus. The small displacement of substrate $F$ determining the width of the microbridge is obtained by switching the bottom end of plate spring I between stops $P$ and $Q$. As the plate springs $H$ are 1000 times as stiff as spring $I$ the substrate will move over $1 / 1000$ of the displacement of piston $\mathbf{R}$.

The displacement of spring $I$ is achieved by pneumatical transport of the piston $\mathrm{R}$ between a fixed stop $\mathbf{P}$ and a variable stop $\mathrm{Q}$. With this very simple method it is possible to obtain displacements of the substrate between 0 and $10 \mu \mathrm{m}$, accurate and reproducible to within $0.05 \mu \mathrm{m}$, without hysteresis.

This bridge fabricating process can be repeated as often as desired along a scratch. For repeated bridge fabrication it is necessary to reset the piston $R$ in between the bridge positions, which can be done while scratching. Dependent on the geometry of the diamond point the minimum distance between parallel bridges across the same scratch is approximately $5 \mu \mathrm{m}$. It is possible to produce parallel scratches each with multiple parallel bridges. The minimum distance between parallel scratches is also approximately $5 \mu \mathrm{m}$, so a « microbridge density » of $10^{4} \mathrm{~mm}^{-2}$ is feasible. As all operations are performed electrically, automatic execution of the whole process is possible. At present in our system only one scratch is produced at a time by our electronic control, while perpendicular displacements are performed by hand. We intend, however, to include electronic control of the movement in the $\mathrm{Y}$ direction. The time required to fabricate one microbridge is $8 \mathrm{~s}$. We expect that this time requirement will limit the total number of microbridges in one array to approximately $10^{4}$. As is shown in figure $3, a, n \times m$ array of microbridges may contain $m$ systems in series each consisting of (Fig. $3 a) n$ microbridges in parallel, or have all $n \times m$ bridges in parallel (Fig. 3b). If all bridges are parallel the voltage across each junction will be the same. The current density in the film might be limiting, however.

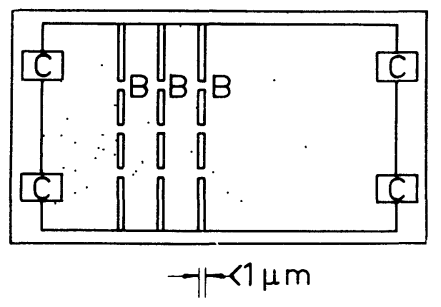

a

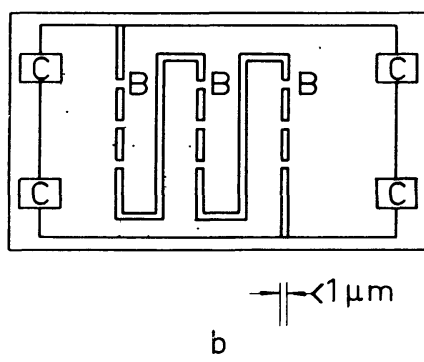

Fig. 3. - Example of possible arrangements of 9 bridges in array. In figure $a$ the film is divided into four different superconducting areas, connected by three parallel bridges B. In figure $b$ all nine bridges are in parallel, the film is separated into two parts only. $c$ are the four electrical contacts. The dotted areas are the metal films.

In figure 4 an electron-microscopical photograph is shown of an array of aluminium microbridges. The bridges along the scratch are $4 \mu \mathrm{m}$ apart, the two scratches are $10 \mu \mathrm{m}$ apart. The scratch itself (the separation between parts of the aluminium film) is at the bottom of the $\mathrm{V}$ shaped groove. With an optical microscope it can be seen immediately after scratching that a curled chip is formed at the end of each part of the scratch. This chip is at that moment still connected to the microbridge, its breaking off causes some uncertainty in the final bridge shape and width. In figure 4 , the round dots at the right hand side of each bridge are the remains of the chips. 
The best results, i. e. the smallest bridges have been obtained with aluminium (scratches 0.5 to $0.8 \mu \mathrm{m}$ wide), but also with tin reasonable bridges have been fabricated (scratches approx. $0.8 \mu \mathrm{m}$ wide). Both on aluminium and tin single bridges microwave induced steps have been observed. Aluminium bridges seem to show a pronounced Dayem-effect (microwave enhanced supercurrent) at temperatures down to $10 \%$ below $T_{\mathrm{c}}$. This will be investigated in more detail.

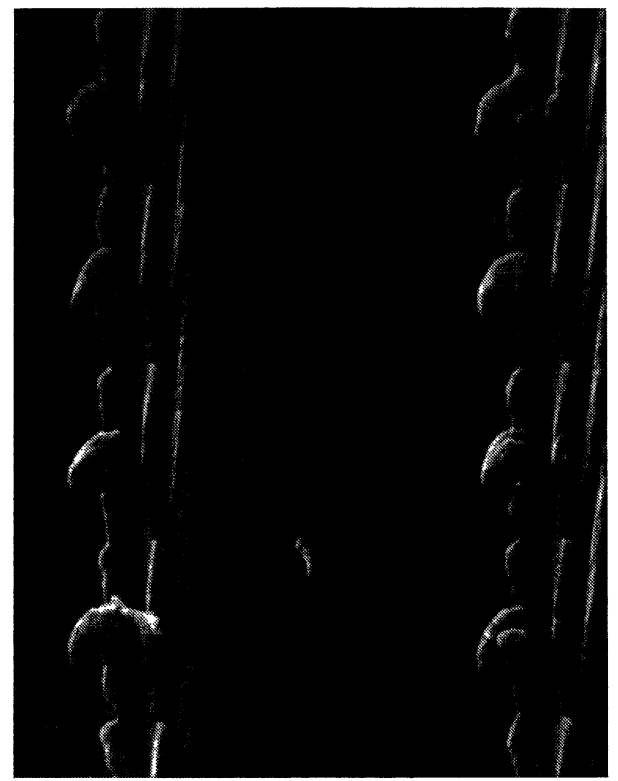

Fig. 4. - Scanning electron-microscopical photograph of part of an array of aluminium microbridges. Scratches are vertical lines $10 \mu \mathrm{m}$ apart. Bridges are $4 \mu \mathrm{m}$ apart.

3. Electron-optical imaging technique. - Photoresist methods of producing patterns in thin metal films are well known. The smallest dimensions that can be controlled are limited by the wavelength of the light employed to approx. $1 \mu \mathrm{m}$. We use a similar procedure in which visible or UV light is replaced by a beam of $14 \mathrm{kV}$ electrons. The apparatus was constructed by the electron-optical department of our laboratory. A cross section is shown in figure 5 .
A mask is mounted in condensor 2 ; the $30 \times$ reduced image of this mask is focused on the surface of the substrate by the objective.

The " electron-sensitive " material employed is poly methyl methacrylate (PMMA). This resist has a very high resolving power [5]. At first we tried to fabricate microbridges with a method mentioned by Hatzakis [5] which needs no etching of the metal. With this method, the substrate is covered with PMMA, which is exposed to electrons in the apparatus. The electrons destroy the polymer chains, making the PMMA easily soluble. In this way a negative image is obtained in the PMMA on the substrate. Now the metal film is evaporated on the substrate and the unexposed PMMA. With a more vigorous dissolving method, the remaining PMMA is removed, taking the metal film on top with it. A positive image is obtained in the metal film. However, if the metal film is thicker than the PMMA film the metal on PMMA and the metal on the substrate are in contact and a bad image results. A thicker PMMA film leads to less well-defined edges in the patterns. The thickness of the metal film is therefore limited. We did obtain very small bridges in this way (approx. $0.3 \mu \mathrm{m}$ wide and long) but in these cases the Sn films employed were too thin to be conducting. By improvement of our evaporation techniques it should be possible to solve this problem.

With a second method, the PMMA is brought onto the metal film. The PMMA is exposed and developed, leaving a negative image of the mask covering the metal films. The unprotected areas of the metal are etched away. An aluminium microbridge produced with this method is shown in figure 6 . The resolution is limited by the etching technique, not by the definition of the image of the mask, or by the resolving power of the PMMA. The smallest bridges of which we were able to determine $I-V$ characteristics were approximately $0.5 \mu \mathrm{m}$ wide.

With our electron-optical imaging device an area of $0.8 \mathrm{~mm}$ diameter is exposed at a time. Both by including more bridges in the mask and by repeated exposure after small displacements of the substrate,

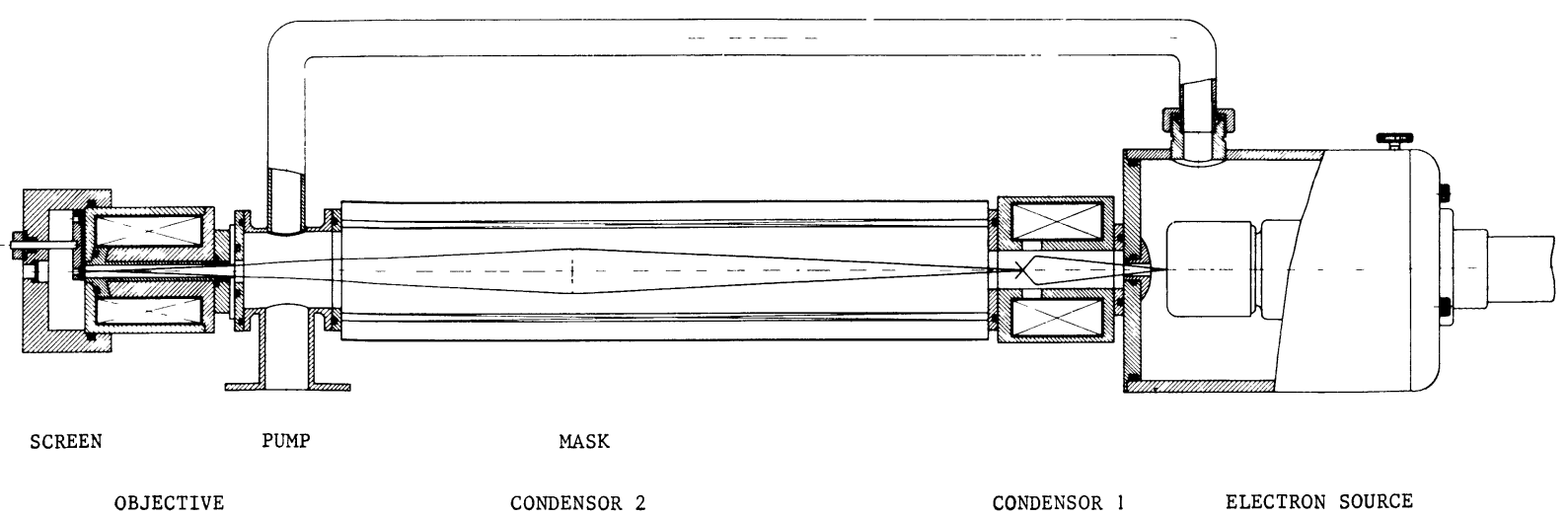

FIG. 5. - Cross section of electron optical imaging apparatus.

Within condensor 2 a mask is mounted which is imaged $(30 \times$ reduced) on the screen or on a substrate at the same position. 
it is possible to extend this technique to the fabrication of arrays of microbridges. As in the time of one exposure (5 s) as many bridges are produced as are contained in the mask (which can be made with conventional photo-resist methods), the total time required puts no limitation to the number of bridges that can be produced.

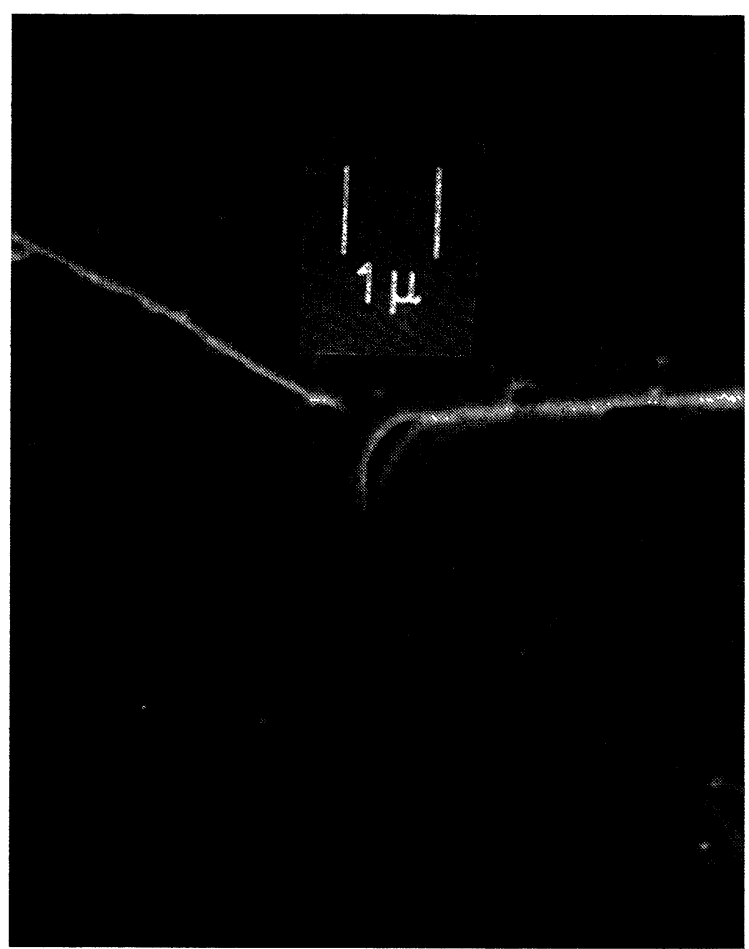

FIG. 6. - Scanning electron-microscopical photograph of an aluminium microbridge fabricated with electron-optical imaging technique.

4. Initial results and considerations for future experiments. - Some preliminary measurements were performed on arrays, produced with the scratching technique. Figure 7 shows the $I-V$ characteristic of a current-driven $30 \times 19$ array of aluminium micro-

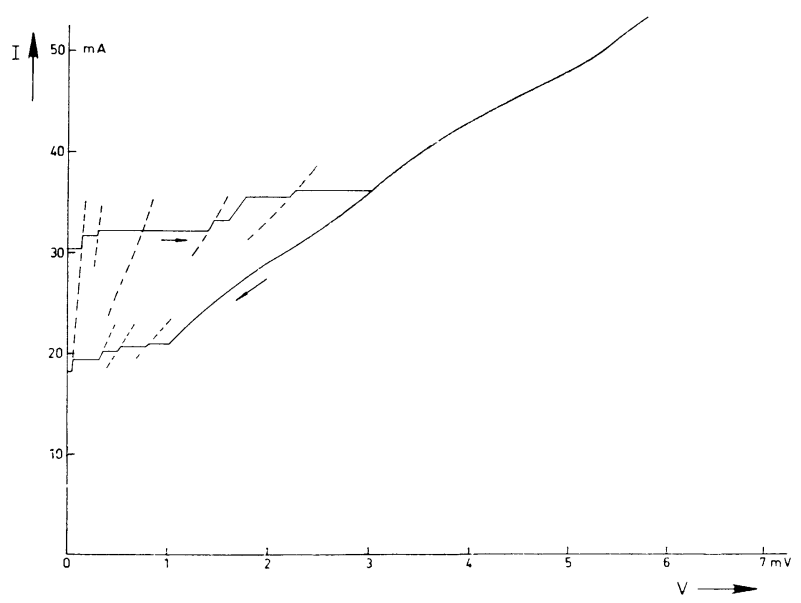

FIG. 7. $-I-V$ characteristic at $1.1 \mathrm{~K}$ of an aluminium $19 \times 30$ array (19 scratches each containing 30 parallel microbridges). Dotted lines are some of the quasi-stable intermediate states. bridges. A considerable amount of hysteresis is observed, as is also the case with our single bridges at this temperature. With increasing current, slightly above $30 \mathrm{~mA}$ (an average of $1 \mathrm{~mA}$ through each junction) a small voltage is developed. Parallel bridges are all in or out of the zero voltage state and effectively this array consists of a series circuit of 19 " scratches ", containing 30 parallel microbridges each. The first jump to a small voltage corresponds to a transition to a resistive state of the scratch with the smallest sum of critical currents. With exactly identical junctions one long jump of all bridges should be observed, without hysteresis but with slightly differing bridges 19 separate transitions should be visible. In fact, the transition of one scratch often seems to trigger the transition of many others so an average of five of six steplike transitions was usually observed. By continuous exploration of the region concerned it was possible to find a large number of quasi-stable intermediate states, some of which are indicated with dotted lines in figure 7 . They each correspond to one particular set of scratches in the totally superconducting and the others in the resistive state. Clark [1] has shown that planar arrays of point contacts between superconducting spheres can be synchronized by external radiation, and can be used as emitters and detectors of high frequency radiation. It will have to be established if planar arrays of microbridges offer the same possibilities. We intend to investigate this, including the influence of the distances between junctions which Clark could not easily vary.

We want to try and use the arrays as resonant detectors in the arrangement shown in figure 8 .

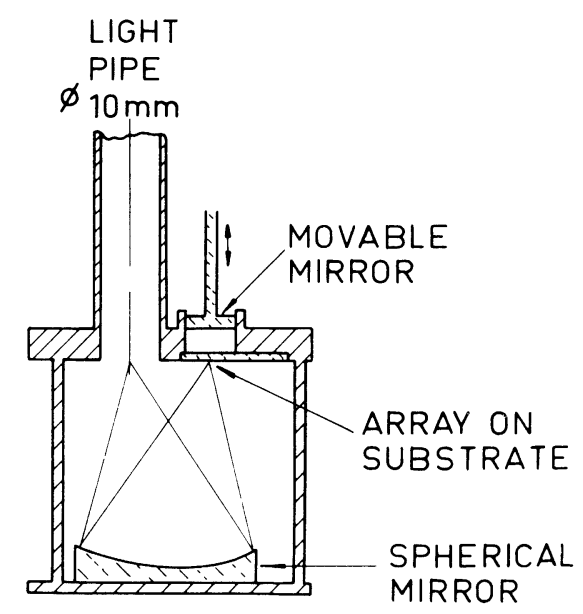

FIG. 8. - Arrangement for resonant detection and emission experiments with arrays of microbridges.

With the aid of a spherical mirror, the far infra-red radiation transported down the cryostat by a circular light pipe is imaged on the array. At the back side of the transparent substrate a flat mirror is placed which can be moved up and down. The back side of the 
array and this mirror form a tunable Fabry-Pérot cavity which can be tuned to the desired frequency.

From the experiments by Clark and by Finnegan and Wahlsten [3] it is clear that multiple junctions in a correlated state are potentially powerful emitters of high frequency radiation. The amplitudes of the radiation emitted by coherent junctions are added rather than the powers, $n$ junctions emit $n^{2}$ the energy emitted by one junction. To synchronize the junctions they must be placed in a cavity in which they are exposed to their own radiation. The geometry of figure 8 should lend itself to this purpose. As stated before, our method is capable of fabricating $10^{4}$ microbridges in a very small area. In a correlated state, these junctions should emit $10^{8}$ times the energy emitted by one bridge. We moreover expect that the arrangement of bridges as pictured in figure $3 b$ will not have to rely very heavily on feedback from a cavity to synchronize the junctions as all junctions are connecting the same bulk superconductors.

Acknowledgments. - Essential advice on the design of the scratching apparatus was obtained from Prof. Dr. D. de Jong.

\section{References}

[1] Clark, T. D., Phys. Rev. B 8 (1973) 137.

[2] Tilley, D. R., Phys. Lett. A 33 (1970) 205.

[3] Finnegan, T. F. and Wahlsten, S., Appl. Phys. Lett. 21 (1972) 541.

[4] Gregers Hansen, P. E., Levinsen, M. T. and Fog PederSEN, G., J. Low Temp. Phys. 7 (1972) 99.

[5] Hatzakis, M., J. Electrochem. Soc. 116 (1969) 1033. 